\title{
Pennies and Eggs: Initiation into Inquiry Learning for Preservice Elementary Education Teachers
}

\author{
Donald J. Wink* and Jeong Hye Hwang-Choe \\ Department of Chemistry, University of Illinois at Chicago, Chicago, IL 60607; *dwink@uic.edu
}

We describe two introductory laboratory activities for a general education course for preservice elementary teachers. Such courses often enroll students who feel alienated from science, so introducing them to new ways of thinking about science is important, for their own learning and in relation to their future teaching $(1-2)$. To address this, we and others created a curriculum focused on the needs and interests of elementary education majors (3). Part of this involved lab materials to develop an understanding of inquiry science. To do this, we have used the science writing heuristic (SWH), since it integrates guided-inquiry methods with writing-to-learn strategies (4-11). Greenbowe and others have shown that the use of the SWH in college courses can deepen understanding (8) and consequently lead to improved performance on lecture quizzes and examinations (5).

Laboratory environments that utilize the SWH approach have students write before, during, and after the lab using a template, which we have adapted to include the following five elements:

1. Beginning ideas

2. Tests

3. Evidence

4. Reflection (done in discussion mode with the instructor)

5. Conclusions and meaning-making (done after the lab period)

This method is unfamiliar to many students, so its effective use requires careful introduction. In this paper we describe the process and experience of incorporating the SWH in two labs that help students learn the heuristic and develop comfort with inquiry learning.

Table 1. Typical Experimental Results for Sets of Five Pennies from Each Decade, 1970s-1990s

\begin{tabular}{|ccccc|}
\hline & & \multicolumn{3}{c|}{ 5 Coins' } \\
\cline { 3 - 5 } Groups & Trials & 1970-1979 & $1980-1989$ & $1990-1999$ \\
\hline A & 1 & 15.4 & 14.3 & 12.5 \\
A & 2 & 15.5 & 13.2 & 12.4 \\
A & 3 & 15.3 & 14.2 & 12.4 \\
B & 1 & 15.4 & 14.3 & 12.5 \\
B & 2 & 15.5 & 14.4 & 12.4 \\
B & 3 & 15.3 & 13.2 & 12.4 \\
C & 1 & 15.5 & 14.3 & 12.5 \\
C & 2 & 15.4 & 14.4 & 12.4 \\
C & 3 & 15.3 & 13.2 & 12.4 \\
\hline
\end{tabular}

\section{An Inquiry into the History of Pennies}

As the first experience for students, we adapted the "penny lab" reported by Mauldin (12). In that work, justifiably recognized as a very good example of discovery learning (13), students consider the mass of individual one-cent coins (pennies) by year. In our case, we let students experience ambiguity in their initial findings, which leads to competing explanations and a second round of experiments. Students begin by conducting a quick survey of masses using sets of five pennies from each decade (1970s, 1980s, and 1990s), obtaining results similar to the data shown in Table 1. These data do not have a clear indication of just when the mass of the penny changed, or even if the change occurred in a particular year.

The relative speed of the beginning question, test design, and data collection (about 40 minutes) leaves time for students to develop and share claims based on evidence in a group-reflection phase. There is wide consensus for the claim that there is a trend where pennies increase in mass as they age. Some students also note that the 1980s pennies have a wider variation than pennies from the 1970s and 1990s. From this they produce several explanations for the trends and variations. One type of explanation is associated with continual change, often attributed to the accumulation of dirt or corrosion; this explanation focuses on evidence from the simple average per decade. A second type of explanation relies on a specific penny-altering event and uses the evidence of the wider variation of masses in the 1980s.

After this reflection phase students return to the "test" phase and conduct a further inquiry to make the data more specific and to test competing explanations. Tests include obtaining the mass of the pennies for particular years, not decades; cleaning older pennies; examining pennies made before 1970 or after 1999; determining the size of pennies (which can be done well by laying pennies side-to-side or stacking up at least 30 pennies); and performing a destructive examination of the interior of pennies.

The classroom work concludes with an understanding that the composition and size of the penny changed in 1982, and that this composition change is associated with a shift from "pure copper" to a coated gray metal core and a slight decrease in thickness $(\sim 3 \%)$. These data explain both the overall decrease in the mass of the penny and also the variation in the 1980s data. Explaining both phenomena strengthens the claim that the 1982 composition change is the only explanation needed.

\section{Sorting Eggs by Properties}

The second science writing heuristic experiment of the semester focuses on physical properties. This is done by considering how to sort different eggs (raw and hard-boiled) from one another. Students receive two eggs of each type with no outside markings. They are asked to develop tests to study the properties of the eggs and to use these properties to sort the eggs. 
Table 2. Sample Student Writing from the Two Inquiry Labs Using the Science Writing Heuristic

\begin{tabular}{|c|c|c|}
\hline SWH Phase & Example Statements from Penny Lab & Example Statements from Egg Lab \\
\hline \multirow{2}{*}{$\begin{array}{l}\text { Beginning } \\
\text { ideas and } \\
\text { questions }\end{array}$} & Does the way pennies are used affect their weight? & Why do some [eggs] float and some sink? \\
\hline & $\begin{array}{l}\text { They can go through chemical substances, dirt, or } \\
\text { just plain too many hands. }\end{array}$ & What happens if the density of the water changes? \\
\hline \multirow[t]{2}{*}{ Tests } & \multirow{2}{*}{$\begin{array}{l}\text { [A]fter weighing all pennies, we will look for any } \\
\text { abnormalities and also compare the average of each } \\
\text { decade. }\end{array}$} & $\begin{array}{l}\text { Check for color/size differences, test the flotation of } \\
\text { eggs in } \mathrm{H}_{2} \mathrm{O} \text { and salt. }\end{array}$ \\
\hline & & $\begin{array}{l}\text { If the egg sinks, we will measure the sodium chloride } \\
\text { that will be put into the water. }\end{array}$ \\
\hline \multirow{3}{*}{$\begin{array}{l}\text { Claim and } \\
\text { evidence } \\
\text { (from same } \\
\text { report) }\end{array}$} & Older pennies are heavier. & \multirow{2}{*}{$\begin{array}{l}\text { I claim that eggs } 3 \text { and } 4 \text { are hard-boiled while eggs } \\
1 \text { and } 2 \text { are not. }\end{array}$} \\
\hline & Evidence in averages: e.g., $1970 \mathrm{~s}$ avg $=3.03 \mathrm{~g}$ & \\
\hline & and $1990 \mathrm{~s}$ avg $=2.49 \mathrm{~g}$ & $\begin{array}{l}\text { I support this claim by first reviewing the observation } \\
\text { recorded. We determined density by using the } \\
\text { equation mass/volume....The second test we did was } \\
\text { the spin test... eggs } 3 \text { and } 4 \text { were of a solid nature. }\end{array}$ \\
\hline \multirow[t]{3}{*}{$\begin{array}{l}\text { Reflections } \\
\quad \text { and } \\
\text { conclusions }\end{array}$} & \multirow{2}{*}{$\begin{array}{l}\text { [A]fter all the testing and observation of my evidence } \\
\text { and my classmates' evidence, there is a clear } \\
\text { understanding that the pennies did differ in the } \\
\text { decades. More importantly, I believe we narrowed } \\
\text { down the time frame of when the change began. }\end{array}$} & $\begin{array}{l}\text { I noticed that by adding salt to water, we created a } \\
\text { solution that increased in density as we increased the } \\
\text { ratio of salt. }\end{array}$ \\
\hline & & \multirow{2}{*}{$\begin{array}{l}\text { Although we changed the density of the solution, the } \\
\text { density of the egg remained the same allowing us to } \\
\text { achieve the same density for both egg and solution. }\end{array}$} \\
\hline & $\begin{array}{l}\text { I found this approach to be more successful because } \\
\text { we actually had to think about what we were } \\
\text { doing, which helped me not only to do the lab, but } \\
\text { understand what I was doing. }\end{array}$ & \\
\hline
\end{tabular}

Student tests initially emphasize observable properties of the eggs, including overall mass, volume, color, and the effects of motion (including spinning). Students note that some quantitative measurements, such as total mass, are easy to do precisely (centigram balances are available for this), while other measurements, such as egg volume, are much less precise. In this case initial claims may be inconsistent, since egg mass itself does not correlate with other properties, such as color or ease of spinning. ${ }^{1}$ An important property they consider is flotation in solutions of different density: for about one month after purchase uncooked eggs sink in pure water but float in salt water, depending on the amount of salt and the type of egg. Observing the flotation of eggs prompts them to consider the relationship of mass, volume, and density qualitatively. They also note that hard-boiled eggs are consistently denser than uncooked eggs. ${ }^{2}$

The class discussion at this point turns to the problem of getting numerical data that do allow consistent sorting of eggs. They know that volume is hard to measure in this case and that mass is an unreliable indicator. So they turn to the problem of measuring the density of the eggs, which in turn requires a second round of tests that lets them "observe" density by measuring the density of the surrounding solution. Typically, eggs increase in density by about $7 \%$ in being hard-boiled. For example, a class of students working with somewhat aged eggs (2-3 weeks after purchase) found raw eggs that had densities that averaged 1.01 $\pm 0.03 \mathrm{~g} \mathrm{~cm}^{-3}$, while eggs from the same batch that were hardboiled had densities that averaged $1.08 \pm 0.04 \mathrm{~g} \mathrm{~cm}^{-3}$.

\section{Hazards}

Neither of these labs poses any significant hazards.

\section{Result and Discussion}

Student data for these labs has been previously noted in Table 1 and in the inquiry lab descriptions above. Illustrations of students' own expressions of results for different parts of the experiments (except the data, mentioned above) are given in Table 2. These provide some indication of how students experience exploration of concepts, ideas, metacognition, and an increase in understanding of the nature of science as a result of these two SWH labs. Students come upon concepts of inquiry that they can use later on, learning to approach lab work in a cycle of data collection, reflection, idea development, and further data collection (14). However, a small number of students show frustration with the extra effort required to complete the lab activities and become discouraged.

We also learned that it is necessary to go over thoroughly what the students have learned via a postlaboratory discussion, something the SWH approach is especially helpful with. The science writing heuristic also supports chemical education research $(7,9-11)$. In this vein we are conducting research using the SWH approach to document how these experiments support growth of inquiry knowledge and also reveal student misconceptions (15-17).

\section{Acknowledgments}

We thank Maria Varelas and Patrick Daubenmire for helpful comments. This work was supported in part by the National Science Foundation, NSF-DUE 0311624. Opinions and findings reported in this paper are the responsibility of the authors and not the NSF. 


\section{Notes}

1. Large eggs have a range in mass of 57-64 g; uncooked eggs at the upper edge of this range weigh more than cooked (hard-boiled) eggs at the lower edge of the range (14).

2. A hard-boiled egg is denser than an uncooked egg of the same freshness for about one day after cooking. Hard-boiled eggs then becomes less dense than an uncooked egg.

\section{Literature Cited}

1. Barton, A. C. J. Curriculum Studies 2000, 22, 797-820.

2. Bianchini, J.; Colburn, A. J. Res. Sci. Teach. 2000, 37, 177209.

3. Varelas, M.; Plotnick, R.; Wink, D.; Fan, Q.; Harris, Y.J. Coll. Sci. Teach., in press.

4. Hand, B.; Prain, V. Sci. Educ. 2002, 86 (6), 737-755.

5. Greenbowe, T. J; Hand, B. Introduction to the Science Writing Heuristic. In Chemists' Guide to Effective Teaching; Pienta, N. J., Cooper, M. M., Greenbowe, T. J., Eds.; Prentice-Hall: Upper Saddle River, NJ, 2005; pp 140-154.

6. Keys, C. W.; Hand, B.; Prain, V.; Collins, S. J. Res. Sci. Teach. 1999, 36, 1065-1084.

7. Burke, K. A.; Greenbowe, T. J.; Hand, B. M.J. Chem. Educ. 2006, 83, 1032-1038.

8. Keys, C. J. Res. Sci. Teach. 2000, 36, 1044-1061.
9. Burke, K. A.; Hand, B.; Poock, J.; Greenbowe, T.J. Coll. Sci. Teach. 2005, 35, 36-41.

10. Hand, B. Int. J. Sci. Educ. 2004, 6, 131-149.

11. Rudd, J. A.; Greenbowe, T. J.; Hand, B. M.; Legg, M. J. J. Chem. Educ. 2001, 78, 1680-1686.

12. Mauldin, R. F. J. Chem. Educ. 1997, 74, 952-955.

13. Herrick, R. S.; Nestor, L. P.; Benedetto, D. A. J. Chem. Educ. 1999, 76, 1411-1413.

14. USDA Egg Market Report. http://www.ams.usda.gov/poultry/ mncs/ShellEgg/2003Reports/011303e.pdf(accessed Nov 2007).

15. Abraham, M. Inquiry and Learning Cycles Approach. In Chemists' Guide to Effective Teaching, Pienta, N. J., Cooper, M. M., Greenbowe, T. J., Eds.; Prentice-Hall: Upper Saddle River, NJ, 2005; pp 41-52.

16. Mullet, E.; Gervais, H. Int. J. Sci. Educ. 1990, 12 (2), 217-226.

17. Rowell, J.; Dawson, C.; Lyndon, Harry. Int. J. Sci. Educ. 1990, 12 (2), 167-175.

\section{Supporting JCE Online Material}

http://www.jce.divched.org/Journal/Issues/2008/Mar/abs396.html

Abstract and keywords

Article PDF with links to cited URLs and JCE articles

Supplement

Student handouts

Instructor notes 